\title{
Risk Factors for Reduced Locomotion in Dairy Cattle on Nineteen Farms in The Netherlands
}

\author{
J. R. Amory, ${ }^{\star 1,2}$ P. Kloosterman,† Z. E. Barker, ${ }^{\star}$ J. L. Wright, ${ }^{*}$ R. W. Blowey, $\ddagger$ and L. E. Green ${ }^{\star}$ \\ *Ecology and Epidemiology Group, Department of Biological Sciences, University of Warwick, UK \\ †PTC ${ }^{+}$Sanjesreed 4/Postbus 85, 9062 EK / 9062 ZJ, Oenkerk, The Netherlands \\ $\ddagger$ Wood Veterinary Group, Gloucester, UK
}

\section{ABSTRACT}

A 3-point locomotion scoring system was used that incorporated the position of the back of cows while standing and when walking to investigate risk factors for elevated locomotion scores of 1,450 dairy cows on 19 farms in The Netherlands. Each of the farms was visited twice in an 18-mo period from February 2003 to July 2004. At each visit, all milking and dry cows were scored for locomotion by a single observer. Two multivariable regression models were constructed to identify factors associated with elevated mean locomotion score (increased abnormality) and the percentage of cows with the highest score (score 3). Risk factors for increased locomotion score were having a hoof-trimming stall with foot-lifting apparatus compared with not having such apparatus (increase in locomotion score $=0.15$ ), presence of a footbath at the parlor exit or other site compared with not having a footbath on the farm (increase in locomotion score $=0.17$ and 0.19 , respectively), not providing supplemental vitamins and minerals to lactating cows compared with supplementing animals (increase in locomotion score $=0.17$ ) and feeding corn silage to heifers compared with not doing so (increase in locomotion score $=0.10$ ). The results provide a framework for hypotheses for future investigations of risk factors for high locomotion scores. Key words: dairy cow, lameness, locomotion score, The Netherlands

\section{INTRODUCTION}

Lameness is a painful condition (Whay et al., 1997) and affects dairy cow well-being by reducing mobility and preventing normal behavior (Farm Animal Welfare Council, 1997). It reduces milk production (Green et al., 2002), fertility (Garbarino et al., 2004), voluntary visits to a robotic milking machine (Klaas et al., 2003),

Received August 9, 2005.

Accepted December 13, 2005.

${ }^{1}$ Corresponding author: jonathan.amory@writtle.ac.uk

${ }^{2}$ Current address: Writtle College, Chelmsford, Essex, UK. and increases replacement rates (Sprecher et al., 1997; Booth et al., 2004). It is also of great economic cost (Green et al., 2002). Economic incentives for milk quality and research have led to improvements in the management of mastitis and SCC in dairy cattle. This is partly due to financial inducement directly assigned to farmers and due to the development of generic recommendations for mastitis control and prevention, such as the 5-point plan (Blowey and Edmondson, 2000). However, there have been few improvements in management of lameness in dairy cattle. Unlike mastitis, there are no direct financial incentives to reduce lameness. Management plans to minimize lameness in dairy cattle have not yet been developed because the research evidence is not robust enough to provide such a plan.

It is clear that there is a high prevalence of lameness and this is the evidence that recommendations are needed, both general and targeted, to reduce lameness. The prevalence of lameness in Europe has been estimated at $1.2 \%$ in 34 zero-grazing herds in The Netherlands (Smits et al., 1992), 5\% on 101 farms in Sweden (Manske et al., 2002), and 22\% on 53 farms in England (Whay et al., 2002). It is possible that the wide variation, both regionally and nationally, in estimates of prevalence of lameness occurs because of the scoring system used and because of different observers.

Observing lameness in cattle and scoring abnormalities in locomotion is subjective. To improve the objectivity of lameness, recording a number of lameness or locomotion scoring systems have been developed (Whay, 2002). However, some of these systems include subjective definitions of their specific scores, for example "...obvious lameness, some difficulty turning..." (Manson and Leaver, 1988); "...slightly lame...markedly lame..." (Tranter and Morris, 1991); and "abnormal locomotion/tender footed...lame..." (Whay et al., 1997). The system developed by Sprecher et al. (1997) uses the position of the back as well as placement of the feet and action in moving, and has clear objective descriptions of posture and gait for scoring, including subdivisions between sound and clinically lame. The system has 5 categories of increasing severity. The first describes a normal locomotion and only considers the back 
position (flat while standing and walking), the next describes a mild abnormality only visible when the animal walks when the back is arched and gait is abnormal. The top 3 scores classify a bovine as lame and observations are arching of the back while standing and walking, and increasingly poor placement of feet.

Despite the limitations of assessment of lameness, there are studies that report associations between management and lameness. Some have focused on the presence of foot lesions and others on actual abnormal locomotion as an indicator of lameness. In the former, solid concrete floors were associated with an increased prevalence of hoof lesions when compared with straw yards around first calving (Webster, 2002), straw yards for milking cows (Somers et al., 2003), slatted-concrete floors (Frankena et al., 1992), and rubber slats (Hultgren and Bergsten, 2001). Increased hoof lesions were associated with reduced lying times (Leonard et al., 1996), discomfort when lying, and the presence of high steps and slopes in housing (Philipot et al., 1994). However, in a recent study, although $2 \%$ of nearly 5,000 cows from 101 farms had hoof lesions, only 5\% were clinically lame (Manske et al., 2002), suggesting that studies of lesions may not be specific to prevent lameness.

Studies in which clinical lameness has been used as the outcome of interest (usually defined by need to give treatment) have associated a high prevalence of lameness with slippery walking areas and uncomfortable stalls (Faull et al., 1996), free stalls compared with tie stalls (Cook, 2003), concrete compared with a sand stall base (Cook, 2003), and the lack of biotin supplementation for milking cows (Hedges et al., 2001). These studies provided associations and are independently insufficient evidence to form the basis of a management program; consequently, it is not yet possible to provide a best-practice management for reducing lameness in dairy cattle from scientific literature. Exposure to different husbandry practices means that risk factors for lameness are likely to vary between farms, management systems, and countries; therefore, a generic and targeted plan is required.

The aim of Lamecow (an European Union framework 5 funded project number OLRT-2001-00969) is to use a multidisciplinary approach to reduce lameness in dairy cows through development of "best practice" in dairy enterprises in member states of the European Union and to understand the biological mechanisms by which lameness is caused and may be minimized. The first stage was to elucidate specific risks. The purpose is to report risk factors identified from an epidemiological study that were associated with increased mean and maximum locomotion scores on 19 farms in The Netherlands.

\section{MATERIALS AND METHODS}

Nineteen farms in The Netherlands (1,450 cows) were enrolled into a study of risk factors associated with high locomotion score in dairy cattle in February 2003. These farms were selected from approximately 500 farms employing 1 of 5 professional hoof trimmers at the convenience of the researchers. Each hoof trimmer worked in one area of the Netherlands, specifically the north, northeast, northwest, east, and south.

The 5 hoof trimmers each visited 4 farms and trimmed all the cattle. Each farm was also visited twice by a researcher (PK), one visit during winter housing and once when the cattle were at pasture, with the exception of one herd that was visited during the housed period only. At each visit, all cows were locomotionscored by PK in confinement or at pasture, using an adaptation of the method of Sprecher et al. (1997), in which scores 3 to 5 were classed as score 3 (Table 1), enabling all scoring to be done using only the position of the cow's back while walking and standing. Farmers completed a questionnaire with questions on management practices that have been hypothesized as risks for lameness (Manske, 2002) including aspects of housing, nutrition, and health for heifers, lactating cows, and dry cows (Table 2 ). In addition, there were observations made directly on the housing environment including cubicle dimensions, bedding and floor types, and external observations of tracks and gateways. Farmers were asked to complete the questionnaire themselves; answers that were unclear were clarified at the subsequent visit by PK.

\section{Data Management and Analysis}

All data were entered into a Microsoft Access database and were examined for errors and missing values that were checked against paper records and, where possible, followed up by contacting the farmer.

The impact of management on locomotion score was assessed in 2 separate models. The individual farm mean locomotion score was calculated by summing the individual cow scores from all visits and dividing by the number of cow observations per farm. The percentage of cows with locomotion score 3 was estimated by summing the number of locomotion score 3 observations from all visits and dividing by the total number of observations. Any differences between the housing and pasture visit locomotion scores was assessed using ANOVA of the farm mean scores.

All independent variables with at least 3 farms in each category were tested first in bivariate linear regression models with mean locomotion score and then with percent locomotion score 3 as the outcome variable. Independent variables with a significance probability 
Table 1. The study locomotion scoring system compared with criteria of Sprecher et al. (1997)

\begin{tabular}{|c|c|c|c|c|}
\hline \multicolumn{3}{|c|}{ Study locomotion scoring system } & \multicolumn{2}{|r|}{ Sprecher et al. (1997) } \\
\hline 1 & Flat & Flat & 1 (normal) & The cow stands and walks with a level-back posture. Her gait is normal. \\
\hline 2 & Flat & Arched & 2 (mildly lame) & $\begin{array}{l}\text { The cow stands with a level-back posture but develops an arched-back } \\
\text { posture while walking. Her gait remains normal. }\end{array}$ \\
\hline 3 & Arched & Arched & 4 (lame) & $\begin{array}{l}\text { An arched-back posture is always evident and gait is best described as one } \\
\text { deliberate step at a time. The cow favors one or more limbs/feet. }\end{array}$ \\
\hline & & & 5 (severely lame) & $\begin{array}{l}\text { The cow additionally demonstrates an inability or extreme reluctance to } \\
\text { bear weight on one or more of her limbs/feet. }\end{array}$ \\
\hline
\end{tabular}

of less than 0.25 were then tested in the general linear multivariate regression models. The multivariate models were developed using manual forward stepwise and backward elimination. The significance probability was set at $P<0.10$. If, after a nonsignificant term was removed, a coefficient changed by $>50 \%$, then that term was retained as a confounder in the model. No interaction terms were tested. After each model was built, all the variables not in the final model were retested individually. Those with a significance $P<0.10$ were then included in the model. All statistical analysis was carried out using S-PLUS for Windows (version 6.2; Insightful Corp., Seattle, WA).

\section{RESULTS}

The mean and standard errors for locomotion score and percent locomotion score 3 was $1.6 \pm 0.03$ (range: 1.2 to 1.9 ) and $16.5 \pm 1.29$ (range: 3.8 to 30.8 ), respectively (Table 3). There was no apparent change in locomotion score by visit (approximately 6 mo between visits). The mean herd size was 76.1 (range: 33 to 113) cows with an average yield of $8,439 \pm 145.8 \mathrm{~kg}$. All of the farms used stall-housing systems, all were bedded with saw- dust apart from one using straw, and all had slatted concrete floors. Eleven farms indicated that they fed some form of supplemental vitamins and minerals to the milking cows (specific mineral and vitamin details were recorded for copper, vitamin $\mathrm{E}$, and biotin only), but no farms fed supplemental biotin in the diet. Further details of these farms are presented in Table 3.

In a univariate analysis, 10 variables were associated with mean locomotion score $(P<0.25)$. The presence of a hoof-trimming stall with foot-lifting equipment, a footbath, copper sulfate in a footbath, keeping sick animals in a separate house, cows not standing after milking before reentering their housing, heifers not given vitamin supplements, milking cows not given vitamin supplements, managing grazing using any method other than set stocking density, and increased average milk yield were associated with elevated locomotion scores (Table 4). Four variables remained in the final model for mean locomotion score (Table 5). These were having a hoof-trimming stall with a foot-lifting apparatus compared with not having such apparatus (mean locomotion score increase of 0.15 ), presence of a footbath at the parlor exit or another site compared with not having a footbath (mean locomotion score in-

Table 2. Areas of risk factors related to locomotion scores of dairy cows on farms from The Netherlands

\begin{tabular}{ll}
\hline \multicolumn{2}{l}{ Farm data recorded } \\
\hline Farmer questionnaire & By direct observation \\
\hline Buildings and building management & Floor types \\
Fields and field management & Bedding type and quantity \\
Lame cow management & Cubicle type and dimensions \\
Use of footbaths & Passageway dimensions \\
Replacement policy & Collecting yard and parlor details \\
Heifer rearing & Tracks and gateways \\
Dry cow management & \\
Transition to milking herd & \\
Milking cow management & \\
Parlor management and milk recording & \\
\hline
\end{tabular}


Table 3. Mean $( \pm \mathrm{SE})$ values for mean locomotion score and percentage of cows with locomotion score $=3$ and main farm variables for 19 dairy herds in The Netherlands

\begin{tabular}{|c|c|}
\hline Farm average locomotion score & $1.6 \pm 0.03$ \\
\hline Proportion of cattle with locomotion score 3 & $16.5 \pm 1.29$ \\
\hline \multicolumn{2}{|l|}{ Stall types, \% } \\
\hline Dutch Supercomfort ('mushroom’) & 16 \\
\hline Newton Rigg & 42 \\
\hline Cantilever & 37 \\
\hline Other & 5 \\
\hline \multicolumn{2}{|l|}{ Wall dimensions, $\mathrm{m}$} \\
\hline Length & $2.30 \pm 0.03$ \\
\hline Width & $1.11 \pm 0.004$ \\
\hline \multicolumn{2}{|l|}{ Center dimensions, $\mathrm{m}$} \\
\hline Length & $2.18 \pm 0.02$ \\
\hline Width & $1.11 \pm 0.005$ \\
\hline Stalls per cow & $1.03 \pm 0.04$ \\
\hline \multicolumn{2}{|l|}{ Bedding, $\%$} \\
\hline Straw & 5 \\
\hline Sawdust & 95 \\
\hline \multicolumn{2}{|l|}{ Lying floor base, \% } \\
\hline Concrete & 68 \\
\hline Mat & 26 \\
\hline Mattress & 5 \\
\hline \multicolumn{2}{|l|}{ Floor cleaning, \% } \\
\hline Automatic scrapers & 32 \\
\hline No scrapers & 68 \\
\hline \multicolumn{2}{|l|}{ Herd size (study distribution), \% } \\
\hline 26 to 50 & 15 \\
\hline 51 to 75 & 30 \\
\hline 76 to 100 & 45 \\
\hline $101+$ & 10 \\
\hline Milk yield, kg & $8,439 \pm 145.8$ \\
\hline
\end{tabular}

crease of 0.17 and 0.19 , respectively), not providing supplemental vitamins and minerals to lactating cows (mean locomotion score increase 0.17), and the inclusion of corn silage in the diet of heifers compared with not doing so (mean locomotion score increase of 0.10 ). The final model for the percentage of locomotion score 3 retained the same variables with the same effect as the mean locomotion score model (data not presented). The residual plot for both models indicated a random distribution of the residuals around the mean.

\section{DISCUSSION}

The locomotion scoring system suggested by Sprecher et al. (1997) was used because of the clear objective descriptions that differentiated each score. Scores 3 to 5 were merged because a large number of cattle could then be scored rapidly using only the position of the back of the cow at standing and walking and also because scores 4 and 5 in Sprecher et al. (1997) identify markedly lame cows; a minimal number of score 4 and 5 animals were expected. Not all cows that arch their back are apparently lame on their feet, but for our study these cattle are assumed to have poor locomotion. Any other condition causing arching of the back would be rare and lead to a slight error. Some cows that were lame did not arch their backs, but again these were a negligible proportion and were not scored as being lame

Table 4. Univariate models for mean locomotion score against individual risk factors for 19 farms from The Netherlands including all terms associated with $P<0.25$, average yield, and herd size $(\mathrm{CI}=95 \% \text { confidence limit })^{1}$

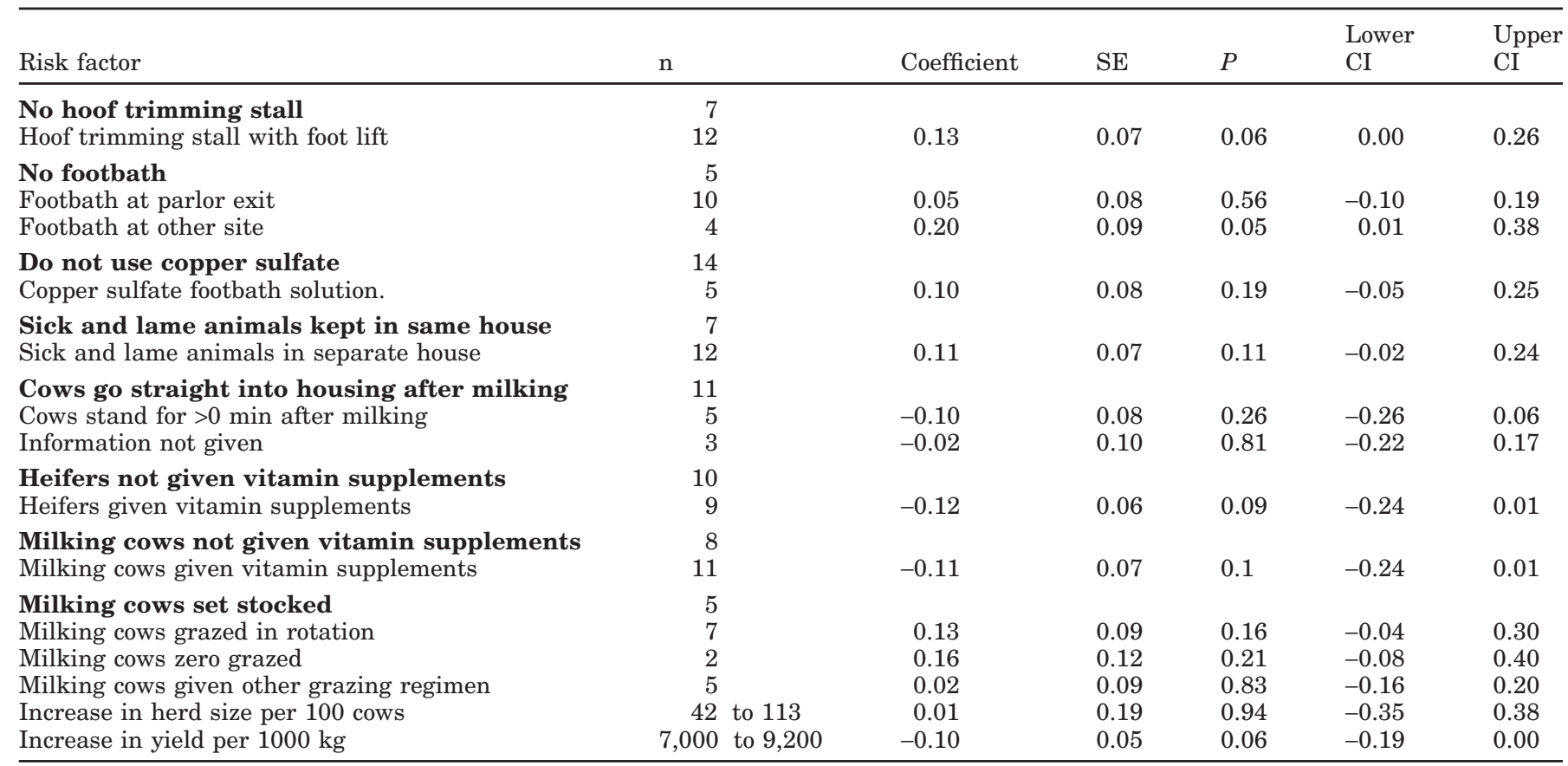

${ }^{1}$ Factors in bold are the reference category for each term. 
Table 5. Final linear regression models for farm mean locomotion score for 19 dairy herds from The Netherlands $(\mathrm{CI}=95 \% \text { confidence limit })^{1,2}$

\begin{tabular}{|c|c|c|c|c|c|c|}
\hline Risk factor & $\mathrm{n}$ & Coefficient & $\mathrm{SE}$ & $P$ & $\begin{array}{l}\text { Lower } \\
\text { CI }\end{array}$ & $\begin{array}{l}\text { Upper } \\
\text { CI }\end{array}$ \\
\hline Intercept & & 1.39 & 0.06 & $<0.001$ & 1.26 & 1.52 \\
\hline $\begin{array}{l}\text { No hoof trimming stall } \\
\text { Hoof trimming stall with foot lift }\end{array}$ & $\begin{array}{r}7 \\
12\end{array}$ & 0.15 & 0.05 & $<0.05$ & 0.05 & 0.25 \\
\hline $\begin{array}{l}\text { No footbath } \\
\text { Footbath at parlor exit } \\
\text { Footbath at other site }\end{array}$ & $\begin{array}{r}5 \\
10 \\
4\end{array}$ & $\begin{array}{l}0.17 \\
0.19\end{array}$ & $\begin{array}{l}0.06 \\
0.07\end{array}$ & $\begin{array}{l}<0.05 \\
<0.05\end{array}$ & $\begin{array}{l}0.04 \\
0.05\end{array}$ & $\begin{array}{l}0.29 \\
0.32\end{array}$ \\
\hline $\begin{array}{l}\text { Milking cows not given vitamin supplements } \\
\text { Milking cows given vitamin supplements }\end{array}$ & $\begin{array}{r}8 \\
11\end{array}$ & -.17 & 0.06 & $<0.05$ & -0.28 & -0.06 \\
\hline $\begin{array}{l}\text { Heifers not fed corn silage }{ }^{3} \\
\text { Heifers fed corn silage }\end{array}$ & $\begin{array}{r}9 \\
10\end{array}$ & 0.10 & 0.05 & 0.063 & 0.00 & 0.20 \\
\hline
\end{tabular}

(P. Kloosterman, personal communication). Using a simple objective scoring system could improve assessment of lameness through its ease of use, and allow quick training of evaluators.

The study herds were larger than the national average (76.1 vs. 60.5 cows, respectively) and produced more milk [8,439 vs. 7,415 average $\mathrm{kg} / \mathrm{cow}$; Productschap Zuivel (2005)]. All farms used a stall-housing system with slatted concrete floors and most bedded using sawdust (one with unchopped straw). Although this is the predominant housing type for The Netherlands it does preclude extrapolation of data to other housing systems such as straw yards (Somers et al., 2003), tie stalls (Cook, 2003), and rubber flooring (Hultgren and Bergsten, 2001). However, the variation of locomotion scores in cows from these homogeneous housing types means that our data could be used in an analytical study to compare the effects of other aspects of management and environment on locomotion score and to generate further hypotheses for study.

The 10 farms on which heifers were fed corn silage as part of their ration had higher locomotion scores than those on which corn was not fed. It has been reported in a study of 80 French dairy farms that the presence of laminitis and interdigital dermatitis was associated with an increased period of feeding corn silage (Faye and Lescourret, 1989) to milking cows. A possible hypothesis for this association is that corn silage causes metabolic disorders because of rapid fermentation in the rumen and a subsequent increase in acidity (Abel et al., 2001). These metabolic disruptions reduce the quality of hoof horn development (Mulling et al., 1999) and may predispose the cow to lameness because of lower resistance to wear. The current findings indicate that this may also be of concern in horn development in younger animals.
Supplementation with minerals and vitamins was associated with a reduction in locomotion score. Previous work has indicated that biotin is associated with a reduction in lameness, specifically white line disease (Hedges et al., 2001). Laboratory studies indicate that both biotin and zinc supplementation improve the quality of developing hoof horn, indicating the biological mechanism for these supplements (Mulling et al., 1999). This study provides further evidence that such supplements assist in reduction of lameness. Although no farms used a specific biotin supplement, these supplements may have balanced corn feeding. It is possible that the inclusion of supplements reflected superior management practice on these farms.

We hypothesize that farmers that recognized a high level of lameness in their herd might have purchased a hoof-trimming stall with lifting equipment as might those who treated their own lame cows. All farms used professional hoof trimmers routinely, but these brought their own hoof-trimming equipment. It is possible that hoof trimming by farmers was detrimental to the locomotion of the cows because of low quality of trimming (Kofler, 1999). Whatever the cause, having such equipment on the farm was associated with an increase, not a decrease, in lameness; the farmer's use of this equipment requires further study. The association between foot trimming by farmers and increased lameness was found in a parallel study in England and Wales (Z. E. Barker, J. R. Amory, J. L. Wright, R. W. Blowey, and L. E. Green, unpublished data). Similarly, the presence of a footbath may indicate a high level of infectious lameness (Sumner and Davies, 1984). Experimental studies indicate that the use of footbaths is beneficial in controlling digital dermatitis (Faye and Lescourret, 1989). A benefit from the use of footbaths was not detectable on commercial farms in this study. This is simi- 
lar to the results of Wassink et al. (2003) in which there was no evidence that foot bathing was associated with a lower prevalence of foot rot (an infectious disease causing lameness in sheep). The lack of efficacy within this study may occur because the farmers did not use the footbath or because the baths were used incorrectly. The latter could include the footbath solution not being changed frequently and becoming contaminated or being too dilute or too concentrated. It might also be that the pit of the footbath became filled with feces and all cows then have to walk through this slurry as they leave to parlor possibly increasing the risk of spread of digital dermatitis.

A number of factors previously associated with increased lameness were not identified in our study. For example, Faull et al. (1996) reported an association between stall design and lameness, but no such association was found here because of the homogeneity in the farms. Epidemiological studies can be used to identify associations, but they cannot identify nonassociation just that there was no difference between an explanatory variable and the outcome.

In summary, aspects of diet, presence of a footbath, and presence of a hoof-trimming stall with foot-lifting gear were associated with poor locomotion. Reduction in lameness did not occur merely because farmers had good hoof-trimming equipment or a footbath. Absence of the role of specific types of housing occurred because of the lack of heterogeneity between farms. We hypothesize that improving diet management, ensuring that farmers can trim feet correctly (or use a trained expert), and using a footbath correctly may assist in lowering the prevalence of high locomotion scores. Elucidation of management practices and the specific lesions causing lameness and their association with locomotion score will assist in identification of targeted interventions.

\section{CONCLUSIONS}

Using linear multivariate models, risk factors for increased abnormality of locomotion were diet (including that of heifers), the presence of a footbath, and the presence of a hoof-trimming stall. Although foot bathing and correct foot trimming can certainly improve locomotion, the presence of such equipment on farm is not sufficient if not used or used improperly. Locomotion may be improved by addressing these areas and either using existing evidence to inform farmers of recommended management or through testing new management strategies to reduce lameness in intervention studies.

\section{ACKNOWLEDGMENTS}

This study is part of a European Union funded framework 5 project (OLRT-2001-00969) “A multidisciplinary approach to the reduction in lameness and improvement in dairy cow welfare in the European Community, Lamecow." The authors thank all the farmers and hoof trimmers who participated in this study. The data collected and locomotion scores used in this study were developed through contributions from all those who attended the first meeting of the European Union Lamecow project in Aberdeen, Scotland, in December 2002. We particularly thank Thomas Manske for his input into this discussion.

\section{REFERENCES}

Abel, H. J., I. Immig, C. D. Gomez, and W. Steinberg. 2001. Research note: Effect of increasing dietary concentrate levels on microbial biotin metabolism in the artificial rumen simulation system (RUSITEC). Arch. Tierernahr. 55:371-376.

Blowey, R., and P. Edmondson. 2000. The environment and mastitis. In Pract. 22:382-394.

Booth, C. J., L. D. Warnick, Y. T. Grohn, D. O. Maizon, C. L. Guard, and D. Janssen. 2004. Effect of lameness on culling in dairy cows. J. Dairy Sci. 87:4115-4122.

Cook, N. B. 2003. Prevalence of lameness among dairy cattle in Wisconsin as a function of housing type and stall surface. J. Am. Vet. Med. Assoc. 223:1324-1329.

Farm Animal Welfare Council. 1997. Report on the Welfare of Dairy Cattle. Ministry of Agriculture, Fisheries and Food, Surbiton, Surrey, UK

Faull, W. B., J. W. Hughes, M. J. Clarkson, D. Y. Downham, F. J. Manson, J. B. Merritt, R. D. Murray, W. B. Russell, J. E. Sutherst, and W. R. Ward. 1996. Epidemiology of lameness in dairy cattle: The influence of cubicles and indoor and outdoor walking surfaces Vet. Rec. 139:130-136.

Faye, B., and F. Lescourret. 1989. Environmental factors associated with lameness in dairy cattle. Prev. Vet. Med. 7:267-287.

Frankena, K., K. A. S. van Keulen, J. P. Noorhuizen, E. N. Noordhuizen-Stassen, J. Gundelach, D. J. de Jong, and I. Saedt. 1992. A cross-sectional study into prevalence and risk indicators of digital haemorrhages in female dairy calves. Prev. Vet. Med. 14:1-12.

Garbarino, E. J., J. A. Hernandez, J. K. Shearer, C. A. Risco, and W. W. Thatcher. 2004. Effect of lameness on ovarian activity in postpartum Holstein cows. J. Dairy Sci. 87:4123-4131.

Green, L. E., V. J. Hedges, Y. H. Schukken, R. W. Blowey, and A. J. Packington. 2002. The impact of clinical lameness on the milk yield of dairy cows. J. Dairy Sci. 85:2250-2256.

Hedges, J., R. W. Blowey, A. J. Packington, C. J. O'Callaghan, and L. E. Green. 2001. A longitudinal field trial of the effect of biotin on lameness in dairy cows. J. Dairy Sci. 84:1969-1975.

Hultgren, J., and C. Bergsten. 2001. Effects of a rubber-slatted flooring system on cleanliness and foot health in tied dairy cows. Prev. Vet. Med. 52:75-89.

Klaas, I. C., T. Rousing, C. F. Fossing, J. Hindhede, and J. T. Sørensen. 2003. Is lameness a welfare problem in dairy farms with automatic milking systems? Proc. 2nd Int. Workshop Assess. Anim. Welfare Farm and Group Level. Anim. Welf. 12:599-603.

Kofler, J. 1999. Clinical study of toe ulcer and necrosis of the apex of the distal phalanx in 53 cattle. Vet. J. 157:139-147.

Leonard, F. C., J. M. O'Connell, and K. J. O'Farrell. 1996. Effect of overcrowding on claw health in first-calved Friesian heifers. Br. Vet. J. 152:459-472.

Manske, T. 2002. Hoof lesions and lameness in Swedish dairy cattle. Ph.D. Diss. Acta Univ. Agric. Sueciae. Vet., Skara, Sweden.

Manske, T., J. Hultgren, and C. Bergsten. 2002. The effect of claw trimming on the hoof health of Swedish dairy cattle. Prev. Vet. Med. 54:113-129.

Manson, F. J., and J. D. Leaver. 1988. The influence of concentrate amount on locomotion and clinical lameness in dairy cattle. Anim. Prod. 47:185-190. 
Mulling, C. K. W., H. H. Braguella, S. Reese, K. D. Budras, and W. Steinberg. 1999. How structures in bovine hoof epidermis are influenced by nutritional factors. Anat. Histol. Embryol. 28:103-108.

Philipot, J. M., P. Pluvinage, I. Cimarosti, P. Sulpice, and F. Bugnard. 1994. Risk factors of dairy cow lameness associated with housing conditions. Vet. Res. 25:244-248.

Productschap Zuivel. 2005. Statistisch Jaaroverzicht 2004 (Statistical Annual Report 2004). Productschap Zuivel, Zoetermeer, The Netherlands.

Smits, M. C. J., K. Frankena, J. H. M. Metz, and J. P. T. M. Noordhuizen. 1992. Prevalence of digital disorders in zero-grazing dairy cows. Livest. Prod. Sci. 32:231-244.

Somers, J. G. C. J., K. Frankena, E. N. Noordhuizen-Stassen, and J. H. M. Metz. 2003. Prevalence of claw disorders in Dutch dairy cows exposed to several floor systems. J. Dairy Sci. 86:2082-2093.

Sprecher, D. J., D. E. Hostetler, and J. B. Kaneene. 1997. A lameness scoring system that uses posture and gait to predict dairy cattle reproductive performance. Theriogenology 47:1179-1187.
Sumner, J., and R. C. Davies. 1984. Footbaths on dairy farms in England and Wales. Vet. Rec. 114:88.

Tranter, W. P., and R. S. Morris. 1991. A case study of lameness in three dairy herds. N.Z. Vet. J. 39:88-96.

Wassink, G. J., R. Grogono-Thomas, L. J. Moore, and L. E. Green. 2003. Risk factors associated with the prevalence of foot rot in sheep from 1999 to 2000. Vet. Rec. 152:351-358.

Webster, A. J. 2002. Effects of housing practices on the development of foot lesions in dairy heifers in early lactation Vet. Rec. 151:9-12.

Whay, H. R. 2002. Locomotion scoring and lameness detection in dairy cattle. In Pract. 24:444-449.

Whay, H. R., D. C. J. Main, L. E. Green, and A. J. F. Webster. 2002. Farmer perception of lameness prevalence. Pages 355-358 in Proc. 12th Int. Symp. Lameness in Ruminants. Orlando, FL.

Whay, H. R., A. E. Waterman, and A. J. F. Webster. 1997. Associations between locomotion, claw lesions and nociceptive threshold in dairy heifers during the peri-partum period. Vet. J. 154:155-161. 